04

\title{
Граничное значение поля, разделяющее области подкритических и глубоко подкритических видов СВЧ-разряда, зажигаемого на диэлектрической поверхности
}

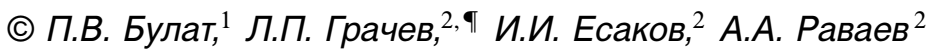 \\ ${ }^{1}$ Университет ИТМО, \\ 197101 Санкт-Петербург, Россия \\ ${ }^{2}$ Московский радиотехнический институт РАН, \\ 117519 Москва, Россия \\ ฯ e-mail: grachev@mrtiran.ru \\ (Поступило в Редакцию 26 марта 2018 г.)
}

Описаны экспериментальные исследования инициированного электромагнитным (ЭМ) вибратором СВЧ-разряда, зажигаемого на внутренней поверхности диэлектрической трубки, помещенной в квазиоптический ЭМ-пучок. В опытах было определено граничное значение уровня СВЧ-поля, разделяющее области подкритических и глубоко подкритических видов СВЧ-разряда. Эксперименты показали, что при определенных условиях стримерные каналы подкритического разряда распространяются от инициатора как навстречу ЭМ-волне, так и вдоль нее. Варьирование мощности СВЧ-пучка позволяло изменять протяженность плазменной области подкритического разряда вдоль волнового вектора СВЧ-пучка и задавать уровень ЭМ-энергии, поглощаемой плазменными областями глубоко подкритического СВЧ-разряда.

DOI: $10.21883 /$ JTF.2019.01.46963.128-18

\section{Введение}

В настоящее время рассматривается вариант пространственно-распределенного многоочагового поджига газовой горючей смеси СВЧ-разрядом с пространственно развитой стримерной структурой [1]. Есть основания предположить, что такой режим поджига позволит приблизиться к теоретически обоснованному энергетически эффективному детонационному режиму горения смеси [2]. Над его реализацией сейчас и работают разработчики соответствующих двигателей [3].

В настоящей работе под СВЧ-диапазоном электромагнитных (ЭМ) колебаний понимаются поля с сантиметровыми-дециметровыми длинами волн $\lambda$, чему соответствует диапазон частот $f \approx(30-2) \mathrm{GHz}$. В рассматриваемых случаях СВЧ-излучение формируется в виде квазиоптического ЭМ-пучка, как правило, линейно поляризованного с ТЕМ-структурой поля. В этом пучке и зажигается газовый электрический разряд [4-7]. Как правило, для реализации таких разрядов при сравнительно высоких газовых давлениях $p$ начальный пробой газа необходимо инициировать. Например, для электрического пробоя воздуха атмосферного состава и давления начальный уровень электрической составляющей ЭМ-волны $E$ должен быть не меньше минимального, критического пробойного уровня $E \mathrm{cr}=30 \mathrm{kV} / \mathrm{cm}$. Для реализации таких значений поля требуются СВЧ-генераторы сверхвысокой мощности $P_{\text {gen. }}$ В связи с этим в реальных экспериментах при высоких значениях $p$ СВЧ-разряды не только инициируются, но и зажигаются в импульсном режиме при длительности СВЧ-импуль-

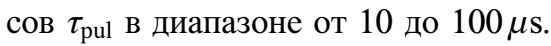

В работах [4-7] рассматриваются различные способы электрического пробоя газа в квазиоптическом СВЧпучке, т. е. инициации СВЧ-разряда. В настоящей работе описываются эксперименты, в которых разряд, как и в работе [4], инициируется ЭМ-вибратором, представляющим собой отрезок металлического провода длиной $2 l$, близкой к резонансной длине $2 l \approx \lambda / 2$. Вибратор помещается в заданную область ЭМ-пучка, как правило, вдоль его вектора $\mathbf{E}$.

В зависимости от уровня поля $E$ и давления газа $p$ виды СВЧ-разряда в квазиоптическом ЭМ-пучке существенно различаются. Так, в воздухе при $p>100$ Torr инициированный разряд в поле с $E<E_{\text {cr, }}$ т.е. так называемый подкритический СВЧ-разряд, представляет собой объемную систему распространяющихся преимущественно навстречу волновому вектору $\mathbf{k}$ ЭМ-волны стримерных каналов. В этом же диапазоне $p$ в поле с $E \ll E_{\text {cr }}$ инициированный уже глубоко подкритический СВЧ-разряд реализуется в виде плазменных областей, которые в течение всего времени $\tau_{\text {pul }}$ локализуются лишь около ЭМ-вибратора. В зависимости от величины $E$ в опытах просматривается сравнительно четкая граница, разделяющая области подкритических и глубоко подкритических СВЧ-разрядов. Так, в воздухе при атмосферном $p$ и $\lambda \approx 10 \mathrm{~cm}$ это граничное значение $E$ имеет величину $E_{\text {thres }}=1.75 \mathrm{kV} / \mathrm{cm}$ [4].

В настоящее время такие разряды зажигались уже как на поверхности помещенного в СВЧ-пучок диэлектрического листа [4], так и на поверхности помещенной в него диэлектрической трубки [1]. При этом если величина граничного поля $E_{\text {thres }}$ при разряде в свободном пространстве определена, то его значение 
при зажигании разряда на диэлектрической поверхности требует определения. Именно такая цель и стояла при проведении описываемых экспериментальных исследований. С практической точки зрения она достаточно актуальна, так как величина $E_{\text {thres }}$ при заданной геометрии СВЧ-пучка позволяет оценить его требуемую мощность $P_{\text {beam. }}$.

\section{Экспериментальная установка}

Эксперименты выполнялись на описанной в работе [4] установке с $\lambda=8.9 \mathrm{~cm}$. Ее схема приведена на рис. 1 .

В опытах использовались одиночные СВЧ-импульсы с прямоугольной огибающей длительностью $\tau_{\mathrm{pul}}=40 \mu \mathrm{s}$. В схеме в отходящий от СВЧ-генератора волноводный тракт включен регулируемый аттенюатор. Он представляет собой контролируемо погружаемую в волновод водяную кювету. В схеме линейно поляризованная ЭМ-волна рупорной антенной излучается в цилиндрическую СВЧ-безэховую герметичную рабочую камеру. Волна падает на сферически вогнутое металлическое зеркало. При этом СВЧ-пучок имеет характерный поперечный размер $50 \mathrm{~cm}$. Отразившись от зеркала, ЭМ-волна фокусируется, формируя линейно поляризованный квазиоптический СВЧ-пучок с ТЕМ-структурой поля. Его фокусное расстояние от среза зеркала $x_{\mathrm{f}} \approx 10 \mathrm{~cm}$. В поперечном сечении распределение поля в фокусной области является гауссовым с характерным размером вдоль вектора $\mathbf{E}-y_{0}=5.2 \mathrm{~cm}$ и поперек $z_{0}=2.5 \mathrm{~cm}$.

Как показано на рис. 1, в СВЧ-пучок вдоль его оси в опытах могла помещаться диэлектрическая трубка. Она выполнена из оргстекла и имела наружный диаметр $40 \mathrm{~mm}$, внутренний $-d=30 \mathrm{~mm}$ и длину $500 \mathrm{~mm}$. На расстоянии $14 \mathrm{~cm}$ от ближайшего к зеркалу торца трубки или на расстоянии $8 \mathrm{~cm}$ от среза зеркала по внутренней поверхности трубки „вдоль“ вектора $\mathbf{E}$ ЭМ-пучка был укреплен дугообразный ЭМ-вибратор. Он представлял собой медный провод диаметром $0.35 \mathrm{~mm}$ и длиной $2 l=45 \mathrm{~mm}$.

Рабочая камера была заполнена атмосферным воздухом и могла откачиваться до $p=10$ Torr с шагом 3 Torr.

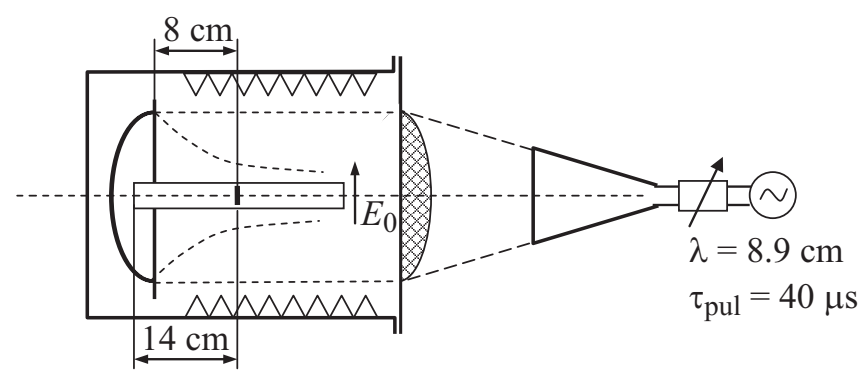

Рис. 1. Схема экспериментальной установки.

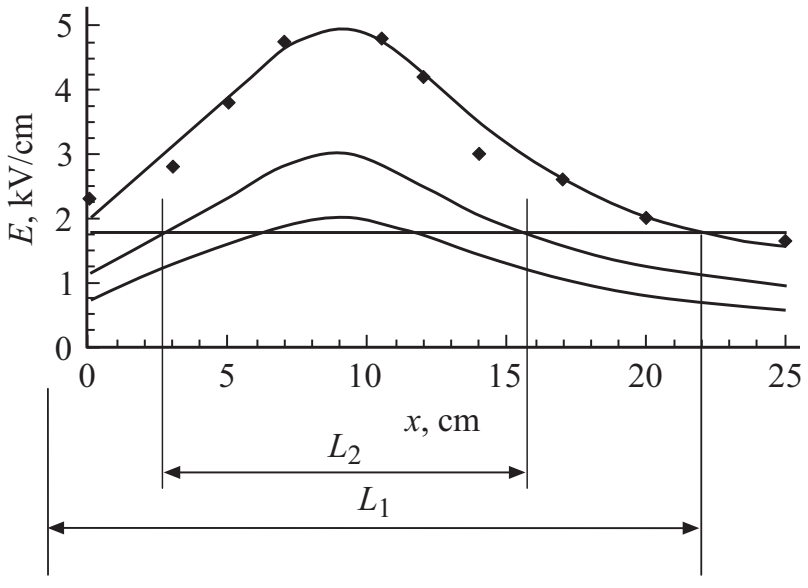

Рис. 2. Распределение величины СВЧ-поля вдоль оси ЭМ-пучка при разной его мощности.

\section{Эксперименты по измерению поля $\mathrm{E}$ в СВЧ-пучке}

Первоначально в опытах было определено распределение поля $E$ вдоль оси ЭМ-пучка при различной степени погружения водяной кюветы аттенюатора в волновод. Эксперименты проводились без помещения в ЭМ-пучок диэлектрической трубки.

В работе [1] приведен экспериментально снятый график зависимости амплитуды поля $E$ от отсчитываемого от среза зеркала расстояния $x$ вдоль оси ЭМ-пучка $E(x)$. Этот график является верхним графиком, помещенным на рис. 2.

В этих опытах использовалась методика, описанная в работе [8]. По ней в требуемую точку ЭМ-пучка помещался металлический шарик. Рабочая камера откачивалась, и определялось максимальное давление воздуха $p_{\mathrm{br}}$, при котором при включении СВЧ-импульса фиксировался пробой воздуха. Для обеспечения наличия вблизи поверхности шарика начальных электронов в течение времени $\tau_{\text {pul }}$ он облучался от удаленного источника ультрафиолетового (УФ) излучения.

Измеренное значение $p_{\mathrm{br}}$ позволяет рассчитать локальное значение амплитуды поля $E$ в „точке“ расположения шарика. Действительно, из электростатики известно, что при диаметре шарика $2 a \ll(\lambda / 4)$ поле на его полюсах, где вектор Е перпендикулярен поверхности шарика, $E_{\mathrm{pol}}=3 E$. При удалении от поверхности шарика индуцированное поле быстро спадает. Следовательно, для реализации процесса размножения начальных электронов, т. е. электрического пробоя воздуха, необходимо, чтобы поле $E_{\text {pol }}$ было больше $E_{\text {cr. }}$ Для воздуха $E_{\text {cr }}$ оценивается по формуле

$$
E_{\mathrm{cr}}=42 p[\mathrm{~V} / \mathrm{cm}]
$$

при размерности $p$ в Torr. В работе [8] приведен рассчитанный и экспериментально проверенный график зависи- 


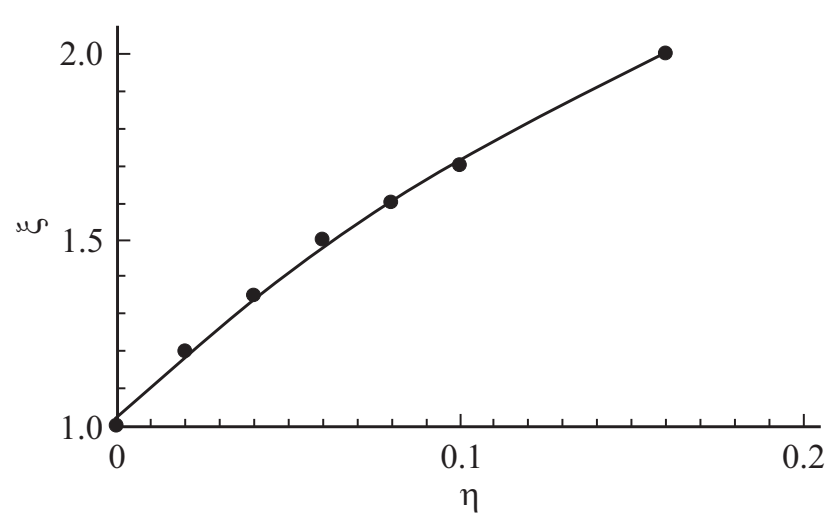

Рис. 3. Зависимость от экспериментальных условий превышения уровня пробойного поля над критическим пробойным уровнем.

мости отношения $E_{\mathrm{pol}} / E_{\mathrm{cr}}=\xi$ от произведения радиуса шарика $a$ на измеренное значение $p_{\mathrm{br}}: \eta=0.84 /\left(a p_{\mathrm{br}}\right)$ при размерности $a-\mathrm{cm}$ и $p_{\mathrm{br}}-$ Torr. Он помещен на рис. 3. В результате поле

$$
E=\left(42 p_{\mathrm{br}} \xi\right) / 3[\mathrm{~V} / \mathrm{cm}]
$$

Эту методику мы использовали и в описываемых опытах. В них металлический шарик диаметром $2 a=5 \mathrm{~mm}$ помещался на оси ЭМ-пучка на расстоянии $x=9 \mathrm{~cm}$ от среза зеркала, т.е. в фокусной области пучка. В экспериментах варьировалась глубина погружения кюветы аттенюатора в волноводный тракт, и при каждом ее значении измерялась величина $p_{\text {br }}$. Затем по этим величинам $p_{\text {br }}$ по (2) рассчитывались поля $E_{0}$, т. е. поля в фокусе ЭМ-пучка при разном уровне его ослабления.

При полностью выведенной из волновода кювете опыты дали $p_{\text {br max }}=327$ Torr или значение $E_{0 \max }=$ $=4.9 \mathrm{kV} / \mathrm{cm}$. Действительно, при этом значении $p_{\mathrm{br}}$ величина $\eta=0.01$ и по графику, приведенному на рис. 3 , ему соответствует $\xi=1.07$. В результате по (2) $E_{0 \max }=4.9 \cdot 10^{3} \mathrm{~V} / \mathrm{cm}$. Это значение поля практически совпало с его величиной, определенной в работе [1] (см. рис. 3). В связи с этим в дальнейших опытах этой серии положение шарика не менялось, а зависимость $E(x)$ аппроксимировалась по данным работы [1] при измеренных значениях $E_{0}$.

При полностью погруженной кювете аттенюатора воздух начинал пробиваться при $p_{\text {br min }}=106$ Torr, что соответствует $E_{0 \mathrm{~min}}=1.8 \mathrm{kV} / \mathrm{cm}$.

Величины $E_{0}$ и параметры поперечной геометрии ЭМ-пучка в фокусной плоскости позволяют рассчитать его мощность $P_{\text {beam: }}$

$$
P_{\text {beam }}=\frac{E_{0}^{2}}{2 Z_{0}} \frac{\pi y_{0} z_{0}}{2},
$$

где $Z_{0}=120 \pi ; \Omega-$ волновое сопротивление свободного пространства. Эта формула дает используемую в опытах максимальную $P_{\text {beam } \max }=650 \mathrm{~kW}$ при $E_{0 \max }$ и минимальную $P_{\text {beam min }}=87.7 \mathrm{~kW}$ при $E_{0 \mathrm{~min}}$.
Так как в опытах, как показано на рис. 1, в ЭМ-пучок помещалась диэлектрическая трубка, то стоял вопрос о величине и конфигурации поля внутри ее объема. Аналитические оценки и численное моделирование показали, что без горения разряда внутри трубки наблюдаются колебания ЭМ-волны. При загорании разряда волна становится „бегущей“ и практически по всей длине трубки величина и конфигурация поля отслеживают исходные параметры. Они незначительно „искажаются“ лишь у торцов трубки на размере масштаба $5 \mathrm{~cm}$.

\section{Результаты и обсуждение основных экспериментов}

В ходе основных экспериментов производилась фоторегистрация разрядной области при различных значениях $E_{0}$. При этом опыты проводились, начиная с максимального значения $E_{0 \max }$ и до $E_{0 \mathrm{~min}}$. При каждом значении $E_{0}$ производилось несколько включений СВЧ-импульса.

Опыты показали, что в диапазоне значений полей от $E_{0 \max }$ до $E_{0 \min }$ разряд был подкритическим, т.е. представлял собой систему стримерных каналов, распространяющихся по внутренней поверхности трубки. При этом при каждом неизменном значении $E_{0}$ в различных импульсах локальная конфигурация стримерных каналов менялась, но длина разрядной области $L$ вдоль трубки при $E_{0}=$ const оставалась неизменной с точностью до нескольких $\mathrm{mm}$. По мере уменьшения $E_{0}$ размер $L$ уменьшался.

Характерные фотографии такого вида разряда помещены на рис. 4. На фотографиях фокусирующее зеркало
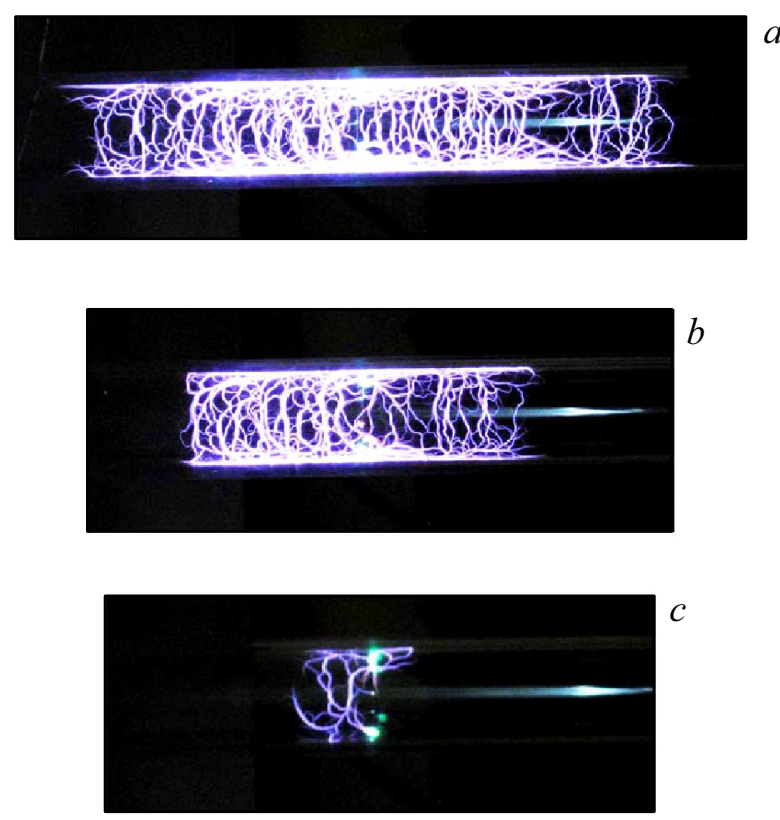

Рис. 4. СВЧ-разряд подкритического вида в квазиоптическом ЭМ-пучке при разном уровне поля $E_{0 \max }, \mathrm{kV} / \mathrm{cm}: a-4.9$, $b-3 \mathrm{kV} / \mathrm{cm}, c-2 \mathrm{kV}$. 


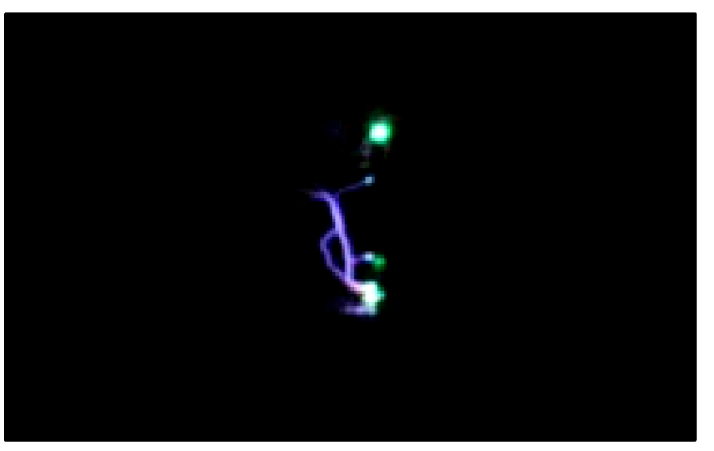

Рис. 5. Инициированный ЭМ вибратором СВЧ-разряд при глубоко подкритическом уровне поля в квазиоптическом ЭМ-пучке.

расположено слева, волновой вектор $\mathbf{k}$ СВЧ-волны имеет направление слева направо и вектор $\mathbf{E}$ вертикален. На фотографиях две вертикально разнесенные яркие плазменные точки расположены у концов инициирующего разряд ЭМ-вибратора. Они наиболее четкие на рис. $4, c$. На рис. $4, a$ и $b$ они расположены практически посередине плазменных областей.

Из рис. 4, с следует, что при малой мощности пучка $P_{\text {beam }}$, т.е. малом поперечном размере его поля со сравнительно большим уровнем, плазменные разрядные каналы экранируют СВЧ-поле в области за инициатором. При этом, естественно, стримерные каналы реализуются лишь в области ЭМ-пучка до инициатора. По

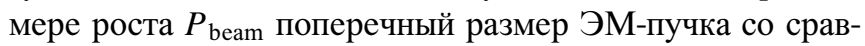
нительно высоким уровнем поля растет, и, как следует из рис. $4, a$ и $b$, стримерные разрядные каналы начинают распространяться от инициатора не только навстречу ЭМ-излучению, но и вдоль вектора $\mathbf{k}$ за инициатором. При этом их „густота“, естественно, падает.

По фотографиям, беря за масштаб изображений наружный диаметр трубки, равный $40 \mathrm{~mm}$, можно определить длины разрядных областей. Так, по рис. 4 длины $L_{1} \approx 24 \mathrm{~cm}, L_{2} \approx 14 \mathrm{~cm}$ и $L_{3} \approx 4.5 \mathrm{~cm}$.

Эти величины $L$ в свою очередь задают искомую величину $E_{\text {thres }} \approx 1.8 \mathrm{kV} / \mathrm{cm}$, отделяющую подкритические и глубоко подкритические виды разрядов. Действительно, на рис. 2, как указывалось, верхний график дает зависимость $E(x)$ при значении поля в фокусной области $E_{0 \max }=4.9 \mathrm{kV} / \mathrm{cm}$. На этом рисунке дополнительно построены аналогичные зависимость $E(x)$ уже при значении поля в фокусной области $E_{0}=3$ и $2 \mathrm{kV} / \mathrm{cm}$. На рис. 2 прямая $E(x)=1.75 \mathrm{kV} / \mathrm{cm}=$ const, пересекая эти зависимости, дает значения длин ЭМ-пучка $L_{1}$ и $L_{2}$ с уровнем поля $E \geq 1.75 \mathrm{kV} / \mathrm{cm}$. Эти величины практически совпадают с измеренными по фотографиям длинами разрядных областей при этих значениях полей $E_{0}$ в фокусной области.

Следовательно, стримерные каналы разряда, зародившись у концов инициатора, при поле $E>E_{\text {thres, }}$ размножаясь, бегут по поверхности трубки, увеличивая длину разрядной области. Добегая до областей ЭМ-пучка с $E=E_{\text {thres }}$, они теряют эту способность и продолжают „жить“ до конца длительности СВЧ-импульса только в этих плоскостях ЭМ-пучка.

По рис. 4, а можно рассчитать среднюю скорость распространения разрядной области по внутренней поверхности трубки $v_{\text {dis }}$ при $\lambda=8.9 \mathrm{~cm}, d=30 \mathrm{~mm}$ и данной геометрией СВЧ-пучка с $E_{0 \max }=4.9 \mathrm{kV} / \mathrm{cm}$ : $v_{\text {dis }}=\left(L_{1} / 2\right) / \tau_{\text {pul }}=6 \cdot 10^{3} \mathrm{~m} / \mathrm{s}$. Это значение $v_{\text {dis }}$ почти в два раза превышает максимальную скорость детонационного распространения пламени, например, по пропанкислородной горючей смеси, равной $2.5 \cdot 10^{3} \mathrm{~m} / \mathrm{s}$ [9].

На рис. 5 приведена фотография разряда, горящего при минимально возможной мощности СВЧ-пучка, т.е. $E_{0 \min }=1.8 \mathrm{kV} / \mathrm{cm}$.

Из фотографии следует, что при таком уровне поля это уже практически разряд глубоко подкритического вида, т.е. его наиболее „энергичные“ плазменные образования локализуются лишь у концов ЭМ-вибратора. Энергию в плазме этих областей принято оценивать по формуле [4]:

$$
Q_{\mathrm{dis}}=\frac{E^{2}}{2 Z_{0}} S_{\mathrm{eff}},
$$

где $E^{2} /\left(2 Z_{0}\right)=\Pi ; \quad J /\left(\mathrm{s} \cdot \mathrm{cm}^{2}\right) \quad$ - плотность потока СВЧ-энергии в области ЭМ-вибратора, а $S_{\text {eff }}-$ эффективная площадь энергетического взаимодействия плазмы инициированного глубоко подкритического СВЧ-разряда с возбуждающим его ЭМ-полем. В настоящее время величина $S_{\text {eff }}$ определена лишь для свободно локализованного разряда такого вида. Так, при $\lambda \approx 10 \mathrm{~cm}$ она лежит в диапазоне $(8-12) \mathrm{cm}^{2}$ [4]. Определение величины $S_{\text {eff }}$ при расположении ЭМ-ибратора на поверхности диэлектрика предполагает дополнительные исследования.

\section{Заключение}

Таким образом, в экспериментах на внутренней поверхности помещенной в квазиоптический СВЧпучок диэлектрической трубки зажжен инициированный ЭМ-вибратором газовый электрический разряд. По результатам их проведения определен граничный уровень СВЧ-поля, отделяющий области подкритических и глубоко подкритических разрядов. По величине он практически совпал с этим уровнем для СВЧ-разрядов в воздухе при атмосферном давлении в свободном пространстве. Значение этого поля задает протяженность разрядной области СВЧ-разряда подкритического вида. Опыты показали, что стримерные каналы этого вида разряда, зародившись у полюсов ЭМ-инициатора, могут распространяться как навстречу СВЧ-волне, так и вдоль ее волнового вектора.

С практической точки зрения наибольший интерес могут представлять изучаемые СВЧ-разряды именно подкритического вида с пространственно-развитой стримерной структурой. При этом при разработке, например, 
импульсных детонационных двигателей такой разряд, как уже продемонстрировано в работе [1], может не только осуществить многоочаговый поджиг газовой горючей смеси, но и за счет ее сгорания в значительном начальном объеме задавать требуемую энергию поджига смеси, необходимую для детонационного фронта распространения пламени по присоединенному объему трубки.

Инициированный глубоко подкритический СВЧ-разряд в диэлектрической трубке может быть реализован при очень малой мощности квазиоптического СВЧ-пучка. Для ее оценки необходимы дальнейшие исследования по определению эффективной площади энергетического взаимодействия СВЧ-поля с разрядной плазмой. Эти исследования, например, могут проводиться с поджигом заполняющей диэлектрическую трубку газовой горючей смеси различного состава, для которой известна величина минимальной энергии ее поджига.

Работа выполнена при финансовой поддержке Министерства образования и науки Российской Федерации (соглашение № 14.577.21.0277, уникальный идентификатор проекта RFMEFI57517X0148).

\section{Список литературы}

[1] Александров К.В., Буслеев Н.И., Грачев Л.П., Есаков И.И., Раваев А.А. // ЖТФ. 2018. Т. 88. Вып. 2. С. 174-179. DOI: 10.21883/0000000000 [Aleksandrov K.V., Busleev N.I., Grachev L.P., Esakov I.I., Ravaev A.A. // Techn. Phys. 2018. Vol. 63. N 2. P. 167-171. DOI: 10.1134/S1063784218020020]

[2] Зельдович Я.Б. // ЖТФ. 1940. № 1 (17). С. 1453-1461.

[3] Булат П.В., Ильина Е.Е. О проблеме создания детонационного двигателя - современные тенденции в аэрокосмическом двигателестроении. Фундаментальные исследования. 2013. № 10. Ч. 10. С. 2140-2142.

[4] Грачев Л.П., Есаков И.И., Александров К.В., Раваев А.А., Северинов Л.Г., Ходатаев К.В. Газовый электрический разряд в квазиоптическом СВЧ-пучке. М.: МРТИ РАН, 2015. $187 \mathrm{c}$.

[5] Батанов Г.М., Грицинин С.И., Коссый И.А., Магунов А.Н., Силаков В.П., Тарасова Н.М. // Труды Физического ин-та им. П.Н. Лебедева АН СССР. 1985. Т. 160. С. 174-203.

[6] Зарин А.С., Кузовников А.А., Шибков В.М. Свободно локализованный СВЧ-разряд в воздухе. М.: Нефть и газ, 1996. 204 c.

[7] Высокочастотный разряд в волновых полях. Сб. науч. тр. ИПФ АН СССР / Отв. ред. А.Г. Литвак. Горький. 1988.

[8] Грачев Л.П., Есаков И.И., Ходатаев К.В., Цыпленков В.В. // Физика плазмы. 1992. Т. 18. Вып. 3. С. 411-415.

[9] Бартльме Ф. Газодинамика горения. М.: Энергоиздат, 1981. $279 \mathrm{c}$. 